\title{
Mapping of Quantitative Trait Loci (QTL) Related to Drought Tolerance in Common Bean (Phaseolus vulgaris L.) Using F2 Population from (KATB1 X GLP2)
}

\author{
Charles Langat ${ }^{1 *}$, Omwoyo-Ombori ${ }^{2}$, Richard Cheruiyot ${ }^{2}$, Moses Gathaara ${ }^{2}$, \\ David Karanja $^{1}$ and Philip Leley ${ }^{1}$ \\ ${ }^{1}$ Kenya Agricultural and Livestock Research Organization (KALRO), Machakos-Kenya \\ ${ }^{2}$ Department of Plant Science, Kenyatta University, Kenya \\ * Corresponding author email: charlestlangat@gmail.com
}

Received: 03 September 2019 / Accepted: 02 October 2019 / Published: 13 October 2019

\begin{abstract}
Many of the common bean growing regions around the world are prone to drought stress, making drought the major challenge to production and yield stability in rainfed environments. Mapping of yield-associated loci under drought stress will offer a better understanding of the genetics of drought tolerance to the plant breeders and therefore, will accelerate the selection of drought tolerant crop varieties through marker assisted selection (MAS).The current study reports identification of quantitative trait loci (QTL) linked to physiological, phenological, yield and yield related traits using $120 \mathrm{~F} 2$ population derived from a cross between two common bean genotypes, KAT B1 (drought tolerant) and GLP2 (drought susceptible) evaluated under drought stress and well-watered conditions. The research was conducted at the Agricultural and Mechanization Institute, Machakos, Kenya. The F2 population showed significant variation in traits under drought stress. From the 374 polymorphic SNP markers surveyed, 20 genomic regions were identified for various traits under drought stress, individually explaining 2.6 to $21.3 \%$ of phenotypic variation. The number of QTLs identified per trait were: 2-grain/seed yield (GY); 1-number of branches (NBP); 2-stem biomass (SB); 1-leaf biomass (LB); 1-pod biomass (PB); 3-days to flowering; 2-days to maturity (DM); 4- number of pods per plant (NPP); 1-seed weight (SW); 2-stomatal conductance (SMTL) and 1-leaf water potential (LWP). QTLs for number of pods per plant, number of grains/seeds per pod, days to flowering, leaf biomass and stem biomass were found co-locating with QTLs for grain yield on chromosome Pv02 under drought stress treatment. The cumulative effects of these QTLs on chromosomes 2 resulted in higher grain/seed yield. This study has provided information on QTLs in common bean that could be used in selection purpose for grain yield under drought conditions.
\end{abstract}

Keywords: common bean, drought, genotypes, markers, QTLs, tolerance, traits.

\section{Introduction}

Drought stress is one of the most serious agronomic challenges affecting common bean production in most tropical and sub-tropical countries $[1,2]$. The effect is particularly severe in regions where production is under rainfed agricultural system in Central America, Eastern and Southern Africa and in many other regions of the world that are already suffering frequent droughts due to global climate change $[3,4,5,6]$.
In the last decade alone, the frequency of drought incidences has increased tenfold resulting in significant yield loses [7]. Approximately 9.8 million metric tons of common beans is lost annually due to drought in Africa [8] and when severe drought occurs early in crop development stages, the yield loss can be up to $80 \%[9,10]$. Keeping in mind that over $80 \%$ of small-holder bean producers in developing countries use unimproved bean cultivars that are notoriously low yielders [11, 12], there is need to select and 
breed for drought tolerant varieties to improve productivity and yield stability under prolonged drought periods.

For decades the majority of efforts towards developing drought tolerant common bean varieties have been carried out through classical approaches. Generally, in classical breeding programs, selection of secondary traits linked to drought tolerance is done using phenotypic measurements [13, 14, 15]. However, considerable difficulties have been encountered with this approach due to complexity of response to drought tolerance and the quantitative nature of yield-related traits, many of them influenced by multiple genes and the environment [16, 17]. According to [18] previous attempts to screen a large germplasm for traits associated with drought tolerance has not been very successful due inherent factors related to low inheritance nature of drought tolerance. Also, the need for multiple environments evaluation of yields over several years further complicate the development of genotypes with improved drought tolerant characteristics as the process involved is often tedious requiring long hours of experimentation, demanding in cost as well as labor intensive. Furthermore, it is difficult to select for drought tolerance under natural environment because of the interaction of drought with other environmental factors such as high temperatures, soil $\mathrm{pH}$ and poor soil fertility $[9,16]$.

Molecular marker technology can be integrated in drought tolerance screening programs to replace classical selection method. Screening a large germplasm of common bean using molecular tools allows the identification of the most promising lines early in the selection process leading to more rapid release of a new variety. The molecular tools using quantitative trait loci (QTL) analysis allows rapid scanning and identification of traits contributing to drought tolerance, eliminating the need for extensive investments and laborious field trials spanning several seasons $[4,19,20,21]$. The analysis of quantitative trait loci (QTL) for drought tolerance under drought stress and non-stress conditions in F2 population would improve the identification of QTL controlling traits associated with broad adaptation to drought stress in common bean thus, opening opportunities to carry out Marker Assisted Selection (MAS) procedure.

The objective of this study, therefore, was to identify the genomic position and the number of quantitative trait loci (QTL) influencing the variation of the number of branches per plant, pod number per plant, grain number per pod, stem biomass, leaf biomass, pod biomass and grain yield in F2 population derived from a cross between two common bean genotypes, KATB1 (drought tolerant) and GLP2 (drought susceptible). This study was conducted under well-watered and drought stress conditions in a rain-out shelter. The information obtained is valuable in helping us to understand the genetic mechanism controlling common bean yield under drought stress conditions. The results may also be directly applicable in marker assisted selection of common bean varieties with drought tolerant abilities.

\section{Materials and Methods}

\subsection{Parental genotypes and mapping population}

A population consisting of $120 \mathrm{~F} 2$ families were raised from selfing $28 \mathrm{~F} 1$ seeds that were obtained from a single cross between KAT B1 (drought tolerant) and GLP2 (drought susceptible) to identify QTL associated with drought tolerance. The two parents differ greatly in terms of grain yield, physiology and phenology traits under drought stress conditions. GLP2, a large red mottled high yielding cultivar was developed in Uganda for high altitude areas. KAT B1 is a medium yellow rounded low yielding line developed by the Kenya Agricultural and Livestock Research Organization (KALRO) adapted to poor soil and water limited environments [22]. Generally, GLP2 yields better than KATB1 under non-stress conditions.

\subsection{Phenotypic evaluation}

The hundred and twenty F2 lines were evaluated along with their parents for physiological, phenological, yield and yield related traits following a randomized block design under two different water treatments; well-watered and drought stress conditions created in a rain-out 
shelter at the Agricultural Mechanization and Research Institute, Machakos, Kenya during 2017-2018.

Five seeds were sown in each plastic pots measuring $(20 \times 20 \mathrm{~cm})$ arranged in three replications within each sub-block. The pots were filled with $7.5 \mathrm{~kg}$ of soil thoroughly mixed with $125 \mathrm{~g}$ of farmyard manure. Two weeks after sowing when seedlings had fully emerged, they were thinned to maintain three per pot. To ensure proper plant establishment and good vegetative growth, each pot was added $1 \mathrm{~L}$ of water each day for fourteen days after emergence. Thereafter, only the non-stress plants continued receiving regular water supply (1L) throughout the experiment, whereas watering was withheld for ten days to induce stress on drought stress plants and later started receiving water only once every seven days.

At the flowering stage, data for different traits were collected from two randomly selected plants within each pot under both well-watered and drought stress conditions. This included days to flower (DF) and number of branches per plant. Data for days to flower (DF) were collected when at least $50 \%$ of the plants within a plot had one fully open flower. At mid-pod filling plant attributes such as number of pods per plant were measured. Data collections for yield related parameters continued at intervals of two days until the plants reached maturity. At harvest time, data on days to maturity (DM) was recorded as the number of days from the date of sowing until when $95 \%$ of the plants in a plot had fully dried pods. Also, data on grain yield, 100-seed weight and yield components were taken on two randomly selected plants within each pot. Selected plants were cut at the base and partitioned into stems, leaves and pods. The individual samples were placed in separate paper bags and oven dried at $80^{\circ} \mathrm{C}$ for 48 hours. The dry weight of each sample was taken to determine the stem biomass $(\mathrm{g})$, leaf biomass $(\mathrm{g})$ and pod biomass (g). Harvest index was calculated from obtained data.

\subsection{DNA extraction and PCR reaction}

The emerging trifoliate leaves of the individual parents and the F2 progenies were harvested and lyophilized. DNA was extracted from the grounded leaves following the modified CTAB protocol described by [23]. After grounding the lyophilized leaves, $300 \mathrm{gm}$ of liquid nitrogen was added and the content transferred into a $1.5 \mathrm{~mL}$ Eppendorf tube, added $500 \mu \mathrm{L}$ of TES extraction buffer and thoroughly agitated and incubated in water bath at $65^{\circ} \mathrm{C}$ for 30 minutes. Afterward $250 \mu \mathrm{L}$ of ammonium acetate solution was added. The preparation was gently shaken and incubated again at $-5^{\circ} \mathrm{C}$ for 10 minutes and the sample was centrifuge for 15 minutes at 15,000 $\mathrm{rpm}$. The supernatant was transferred to a new Eppendorf tube and added $500 \mu \mathrm{L}$ of ice-cold isopropanol solution and the mixture incubated at $-20^{\circ} \mathrm{C}$ for 2 hours. The mixture was centrifuge for 10 minutes at 15,000 rpm to pellet the DNA. After decanting the supernatant, DNA pellet was washed with $800 \mu \mathrm{L}$ of $70 \%$ ethanol. The DNA was then air dried for 15 minutes and dissolved in $250 \mu \mathrm{L}$ of $1 \mathrm{XTE}$ buffer. The DNA solution was transferred to a $1.5 \mathrm{~mL}$ tube and $5 \mu \mathrm{l}$ of RNase A $(20 \mathrm{mg} / \mathrm{mL})$ was added and incubated at $37^{\circ} \mathrm{C}$ for 1 hour.

\subsection{Genotyping}

\subsubsection{Amplification of microsatellites and detection of their polymorphisms}

PCR amplification was performed in a $10 \mu \mathrm{l}$ of total reaction mixture composing of $50 \mathrm{\eta g} / \mu \mathrm{l}$ genomic DNA, $0.5 \mu \mathrm{l}$ of each reverse and forward primer $(10 \mathrm{mM})$ added to a PCR-premix containing, $1.0 \mu \mathrm{l} 25 \mathrm{mM} \mathrm{MgCl}_{2}, 0.2 \mathrm{mM}$ dNTP and 0.4U DNA Taq Polymerase. The mixture was brought to the mark by adding molecular grade water. The initial step of thermal profile involved hybridization at $96^{\circ} \mathrm{C}$ for 3 minutes, followed by denaturation at $94^{\circ} \mathrm{C}$ for $20 \mathrm{~s}$, annealing at $55^{\circ} \mathrm{C}$ for $35 \mathrm{~s}$, extension at $72^{\circ} \mathrm{C}$ for 2 minutes, with a final extension at $72^{\circ} \mathrm{C}$ for 5 minutes. The denaturation, annealing and first extension process was each repeated for 35 cycles.

After PCR, the amplified products were then separated by electrophoresis in $1.2 \%$ agarose gel, stained with $0.5 \mu \mathrm{g} / \mathrm{ml}$ ethidium bromide. Polymorphisms was visualized using UV transilluminator. The SNP genotyping was conducted on the BeadXpress Illumina platform 
following the 10 Infinium ${ }^{\circledR}$ HD Assay Protocol and the SNP calling was completed using the program Genome Studio Genotyping version v1.8.4 (Illumina, Inc., US).

\subsubsection{QTL analyses}

A genetic linkage map of the common bean F2 population was constructed using the software JoinMap v.4.0 at minimum logarithm of odd (LOD) scores of 5.1 between markers [24]. The order of markers in each linkage group was established by maximum likelihood method. Kosambi mapping function [25] was used to convert the recombination frequencies to marker distances in centiMorgans (cM). The whole genome Phaseolus vulgaris map version 1.0 was the reference in locating the physical position of the SNP markers $[26,27]$. QTL analysis for each trait was conducted through the composite interval mapping (CIM) of Win QTL cartographer 2.5 software [28]. Initially, the genomic position of markers associated with drought tolerance was identified through single marker analysis (SMA). Markers and the target trait showing significant association at a $\mathrm{p} \leq 0.05$ were considered to identify the same QTL. Then, CIM was performed to locate QTL regions more accurately using a model with a window size of $10 \mathrm{cM}, 1 \mathrm{cM}$ walk speed, 5 significant background markers and a reverse forward linear regressions for each chromosomal position [29]. LOD thresholds score $(p \leq 0.01)$ for defining the position of significant QTL was determined using 1000-permutation test runs for each trait [30]. Peak LOD threshold score of 3.0 was set for identifying QTLs based on the permutation results. Finally, designation of the identified QTL refers to QTL nomenclature guidelines for common bean $[14,31,32]$. Three parts were included; abbreviation for the trait name, linkage groups designation number and the serial number of the QTL controlling a trait. For example, in this QTL, SY2.3KG, SY is the abbreviation for the trait; seed yield, the first number shows the location and for this case is chromosome 2 (Pv02), while the second number (3) indicates the order of discovery of this QTL and the superscript ' $K G$ ' is the abbreviation for the population name i.e. KATB1/GLP2.

\subsection{Statistical analysis}

The SAS v9.3 software of [33] was used to conduct statistical analysis for all the traits in both non-stress and drought-stress conditions. The effect of water treatment on the F2 population was performed using PROC MIXED model procedure in which the replications were considered as random effects whereas water treatment and genotypes were treated as fixed effects. The correlations among variables were obtained by using The PROC CORR command of the Statistical Analysis System SAS.

\section{Results}

\subsection{Phenotypic Trait Variation and Correlation}

Data for the various phenotypic traits measured among the F2 families and the parental lines are presented in (Table 1). Results show that the response of $\mathrm{F} 2$ population to water treatment varied significantly for all traits studied. Drought stress treatment significantly $(\mathrm{p} \leq 0.05$ and $\mathrm{p} \leq$ 0.01) affected all the traits except only for number of seeds per pod, and the number of days to maturity. Significant differences $(p \leq 0.01)$ were found among all the traits for genotypewater treatment interactions except number of days to flower and number of pods per plant. KATB1 and GLP2 differed significantly $(\mathrm{p} \leq$ 0.05 ) for number of branches per plant, number of pods per plant and the number of seeds per pod in drought stress treatment and not in wellwatered conditions. The differences for three traits within the F2 population were highly significant $(\mathrm{p} \leq 0.01)$ in both treatments (Table 1). Meanwhile, KATB1 flowered and matured earlier than GLP2 in either treatment. Similarly, among the F2s the tolerant population flowered and matured earlier compared with the susceptible group (Table 1).

Overall, for the F2 population, days to flowering varied from 36 to 31 implying that flowering occurred 3 days earlier in drought stress than in well-watered conditions. A difference of 6 days between well-watered and drought stress conditions was also noticed on average for the number of days to maturity that varied from 60 to 76 days. 
Table 1: Statistical analysis for traits for KATB1 X GLP2, and 30 most susceptible (SS) and 30 most drought tolerant $(D T)$ population $(P)$ studied in a rain out shelter under well-watered and drought stress treatments

\begin{tabular}{|c|c|c|c|c|c|c|c|c|c|}
\hline \multirow[b]{2}{*}{ Trait } & \multirow[b]{2}{*}{ Trt } & \multicolumn{2}{|c|}{ Parents } & \multirow[b]{2}{*}{ Diff. } & \multicolumn{5}{|c|}{ F2 population } \\
\hline & & KATB1 & GLP2 & & $\begin{array}{c}\text { SS } \\
\text { population }\end{array}$ & $\begin{array}{c}\text { DT } \\
\text { population }\end{array}$ & $\mathbf{P}$ & Trt & $\begin{array}{l}\text { P } \times \\
\text { Trt }\end{array}$ \\
\hline \multirow[b]{2}{*}{ Number of branches/plants } & ww & 10.8 & 11.2 & ns & 9.8 & 12.6 & $* *$ & $*$ & $* *$ \\
\hline & DS & 8.9 & 6.4 & $*$ & 7.3 & 11.7 & $* *$ & $* *$ & $*$ \\
\hline \multirow[b]{2}{*}{ Number of pods/plants } & ww & 13.6 & 14.2 & $\mathrm{~ns}$ & 9.1 & 14.6 & $* * *$ & $* *$ & $*$ \\
\hline & DS & 11.8 & 9.7 & $*$ & 7.5 & 12.5 & $* *$ & $* * *$ & ns \\
\hline \multirow[b]{2}{*}{ Number of seed/pods } & ww & 4.2 & 4.6 & ns & 2.5 & 5.7 & $* *$ & ns & $* *$ \\
\hline & DS & 3.8 & 2.2 & $* * *$ & 3.6 & 4.8 & * & $\mathrm{ns}$ & $*$ \\
\hline \multirow[b]{2}{*}{ Days to flowering } & ww & 31.0 & 36.0 & $* *$ & 35.9 & 31.4 & $*$ & $*$ & ns \\
\hline & DS & 30.5 & 35.4 & $* *$ & 35.0 & 30.2 & $*$ & $* *$ & ns \\
\hline \multirow[b]{2}{*}{ Days to maturity } & ww & 48.6 & 58.4 & $* *$ & 57.3 & 48.2 & $* *$ & ns & $*$ \\
\hline & DS & 46.7 & 54.2 & $* *$ & 52.6 & 46.1 & $* *$ & ns & $* *$ \\
\hline \multirow[b]{2}{*}{ Stem biomass } & ww & 3.21 & 3.45 & $\mathrm{~ns}$ & 3.35 & 4.1 & $* *$ & $*$ & $* *$ \\
\hline & DS & 3.01 & 2.65 & ns & 2.84 & 3.63 & $*$ & $* * *$ & $*$ \\
\hline \multirow[b]{2}{*}{ Leaf biomass } & ww & 4.24 & 5.53 & ns & 4.05 & 5.24 & $*$ & $* *$ & $* * *$ \\
\hline & DS & 3.75 & 3.08 & ns & 3.21 & 4.20 & $*$ & $*$ & $*$ \\
\hline \multirow[b]{2}{*}{ Pod biomass } & ww & 2.13 & 2.34 & $\mathrm{~ns}$ & 1.18 & 3.45 & $* *$ & $* *$ & $* *$ \\
\hline & DS & 2.05 & 1.12 & $*$ & 1.18 & 3.18 & $* *$ & $* * *$ & $*$ \\
\hline \multirow{2}{*}{$\begin{array}{l}\text { 100-seed weight } \\
\text { (gm/100seeds) }\end{array}$} & ww & 28.11 & 30.76 & $\mathrm{~ns}$ & 26.21 & 34.24 & $* *$ & $*$ & $\mathrm{~ns}$ \\
\hline & DS & 24.23 & 22.83 & $\mathrm{~ns}$ & 23.42 & 32.93 & $* *$ & $* *$ & ns \\
\hline \multirow[b]{2}{*}{ Grain yield (gm/plant) } & ww & 8.04 & 8.91 & ns & 8.12 & 9.55 & $*$ & $* * *$ & $*$ \\
\hline & DS & 7.63 & 5.49 & $*$ & 4.48 & 8.79 & $* *$ & $*$ & $* *$ \\
\hline \multirow[b]{2}{*}{ Stomatal conductance } & ww & 31.2 & 25.5 & $*$ & 21.6 & 37.8 & $*$ & $*$ & $*$ \\
\hline & DS & 38.7 & 27.3 & $*$ & 19.5 & 43.6 & $* *$ & $* *$ & $*$ \\
\hline \multirow[b]{2}{*}{ Leaf water potential } & ww & -0.48 & -0.49 & $*$ & -0.49 & -0.49 & ns & $\mathrm{ns}$ & ns \\
\hline & DS & -0.59 & -0.63 & $*$ & -0.68 & -0.55 & $*$ & $*$ & $* *$ \\
\hline
\end{tabular}

Meanwhile, drought stress tolerant and susceptible F2 plants produced an average grain yields of $8.79 \mathrm{~g}$ and $4.48 \mathrm{~g}$ whereas those under well-watered conditions produced $9.55 \mathrm{~g}$ and 8.12 $\mathrm{g}$ respectively. Among the parents, grain yield varied from 5.49 to $7.63 \mathrm{~g}$ under drought stress conditions while the range was from 8.04 to 8.91 $g$ in well-watered conditions. The parental differences in terms of seed weight were significant $(\mathrm{p} \leq 0.05)$ in either treatments while for the F2 population the differences were significantly high $(\mathrm{p} \leq 0.01)$ in both conditions. Average seed weight for susceptible F2 population across treatments was 26.21 and 23.42 $\mathrm{g}$ per 100 seeds for susceptible and 34.24 and $32.93 \mathrm{~g}$ per 100 seeds for tolerant under wellwatered and drought stress respectively. The seed weight across treatments for the parental lines ranged from 22.83 to $24.23 \mathrm{~g}$ per 100 seeds under drought stress conditions and from 28.11 to $30.76 \mathrm{~g}$ per 100 under well-watered conditions.
Therefore, transgressive segregation for seed weight was therefore evident. Some of the F2 progenies were heavier or lighter in weight than the drought tolerant parent KATB1 or the susceptible parent GLP2. Likewise, transgressive segregation was also observed for grain yield, number of branches, pod number and seed number as well as for the phenological traits.

Correlation coefficients of various traits under well-watered and drought stress treatments are presented in table 2. Positively strong and significant correlations were found between biomass traits including stem biomass, leaf biomass and pod biomass and the phenological traits; days to flowering and days to maturity under drought stress, while a negative but significant correlations were observed between number of pods per plant and number of grains per plant and phenological traits under similar conditions. The number of pods per plant had significant correlation with seed yield under both 
Mapping of Quantitative Trait Loci (QTL) Related to Drought Tolerance in Common Bean............

treatments. Days to flowering showed a significant correlation with grain yield only under well-watered conditions. At drought stress treatment the correlation was not significant, in contrast, days to maturity was negatively correlated with grain yield only under drought stress treatment. A positive and highly significant correlation was also observed between the stomatal conductance and the with grain yield under drought stress treatment. A negative but significant correlation was observed between the leaf water potential and stem and leaf biomass under drought treatment. Under well water treatment, non- significant negative correlation was recorded between 100-seed weight and grain yield, but significant positive correlation was observed under drought stress.

\subsection{QTL analysis}

SNP profiling yielded 1578 polymorphic markers, however, after omitting redundant and clustered markers, only a total of 374 of these markers were mapped in KATB1/GLP2 F2 population across 11 chromosomes spanning a total length of $754 \mathrm{cM}$ of the bean genome at an average distance of $2.02 \mathrm{cM}$ between adjacent markers (Table 3). The chromosomes sizes ranged between $23.4 \mathrm{cM}$ and $116.5 \mathrm{cM}$ with chromosome Pv04 being the shortest at $23.4 \mathrm{cM}$, while chromosome $\mathrm{Pv} 07$ was the longest with $116.5 \mathrm{cM}$. The highest number of co-segregating markers were detected on chromosome $\mathrm{Pv} 02$ as indicated by the smaller genetic distances suggesting lower rates of recombination (Table 3).

Table 3: Distribution of SNPs markers mapped across the eleven chromosomes of common bean in KATB1 X GLP2 F2 population

\begin{tabular}{|c|c|c|c|}
\hline Chromosome & $\begin{array}{l}\text { No. of } \\
\text { markers }\end{array}$ & $\begin{array}{l}\text { Length } \\
(\mathrm{cM})\end{array}$ & $\begin{array}{l}\text { Average } \\
\text { distance } \\
\text { between } \\
\text { markers } \\
(\mathrm{cM})\end{array}$ \\
\hline Pv01 & 34 & 107.9 & 3.10 \\
\hline Pv02 & 87 & 77.1 & 0.72 \\
\hline Pv03 & 56 & 104.5 & 3.27 \\
\hline Pv04 & 18 & 23.4 & 1.21 \\
\hline Pv05 & 22 & 84.3 & 2.59 \\
\hline Pv06 & 30 & 45.1 & 1.65 \\
\hline Pv07 & 28 & 116.5 & 3.01 \\
\hline Pv08 & 41 & 65.0 & 1.76 \\
\hline Pv09 & 4 & 11.9 & 2.38 \\
\hline Pv10 & 9 & 46.7 & 6.54 \\
\hline Pv11 & 45 & 71.6 & 1.37 \\
\hline TOTAL & 374 & 754 & 2.02 \\
\hline
\end{tabular}

SNP; single nucleotide polymorphism, cM; CentiMorgan

Table 2: Pearson correlation coefficients between various traits in the F2 population

\begin{tabular}{|l|c|c|c|c|c|c|c|c|c|c|c|c|}
\hline & NBP & NPP & NGP & SB & LB & PB & 100-SW & SY & DF & DM & STCO & LWP \\
\hline NBP & - & $0.56^{* *}$ & $0.52^{* *}$ & $0.44^{*}$ & 0.08 & 0.16 & 0.03 & $0.71^{* *}$ & 0.04 & 0.11 & 0.18 & 0.09 \\
\hline NPP & $0.62^{* *}$ & - & $0.49^{*}$ & $0.58^{* *}$ & 0.11 & 0.11 & 0.08 & $0.60^{* *}$ & $-0.43^{*}$ & $-0.52^{* *}$ & 0.07 & 0.12 \\
\hline NGP & $0.50^{*}$ & $0.48^{*}$ & - & $0.40^{*}$ & 0.05 & 0.10 & 0.02 & $0.60^{* *}$ & $-0.40^{*}$ & $-0.39^{*}$ & 0.22 & 0.02 \\
\hline SB & $0.39^{*}$ & 0.23 & 0.05 & - & 0.15 & 0.03 & 0.17 & 0.05 & $-0.53^{* *}$ & $-0.56^{* *}$ & 0.24 & $-0.31^{*}$ \\
\hline LB & $0.41^{*}$ & 0.25 & 0.14 & 0.11 & - & 0.11 & 0.05 & 0.07 & $-0.66^{* *}$ & $-0.59^{* *}$ & 0.09 & -0.44 \\
\hline PB & $0.54^{* *}$ & -0.22 & 0.13 & 0.03 & 0.10 & - & -0.15 & 0.10 & $-0.64^{* *}$ & $-0.55^{* *}$ & 0.25 & 0.21 \\
\hline $\mathbf{1 0 0 - S W}$ & $0.35^{*}$ & 0.26 & -0.24 & 0.17 & -0.21 & -0.13 & - & $0.38^{*}$ & $-0.37^{*}$ & $-0.31^{*}$ & 0.33 & 0.24 \\
\hline SY & $0.68^{* *}$ & $0.51^{* *}$ & $0.51^{* *}$ & $0.42^{*}$ & $0.45^{*}$ & 0.07 & -0.10 & - & 0.23 & $-0.45^{*}$ & $0.71^{* * *}$ & 0.10 \\
\hline DF & 0.12 & 0.04 & 0.18 & $-0.49^{*}$ & -0.20 & -0.22 & $0.57^{* *}$ & $0.47 *$ & - & $0.30^{*}$ & $0.32^{*}$ & 0.03 \\
\hline DM & 0.09 & 0.15 & 0.27 & $-0.37^{*}$ & -0.07 & -0.16 & $0.63^{* *}$ & 0.28 & $0.33^{*}$ & - & 0.28 & $0.43^{*}$ \\
\hline STCO & 0.15 & 0.26 & 0.22 & 0.17 & 0.11 & 0.13 & 0.05 & 0.20 & 0.07 & -0.23 & - & $0.33^{*}$ \\
\hline LWP & 0.12 & 0.04 & 0.18 & $0.39^{*}$ & 0.20 & 0.22 & 0.17 & $0.37^{*}$ & $0.34^{*}$ & 0.30 & 0.22 & - \\
\hline
\end{tabular}

*** and *** represent the statistical significance at $0.05,0.01$ and 0.001 probability level. NBP; number of branches per plant, NPP;

number of pods per plant, NGP; number of grains per plant, SB; stem biomass, LB; leaf biomass; PB; pod biomass, $100 \mathrm{SW}$; 100 seed weight, SY; seed yield; DF; days to flowering, DM; days to maturity, STCO; stomatal conductance, LWP; leaf water potential. The values above diagonal are correlation coefficients among traits under drought stress conditions; values below diagonal are correlation coefficients among traits under well-watered conditions 
Langat et al., Int. Ann. Sci.; Vol. 8, Issue 1, pp: 75-86, 2020

Table 4: Identification of quantitative trait loci for number of branches(NB), number of pods (NP), number of grains (NG), days to flowering (DF), days to maturity (DM), stem biomass (SB), leaf biomass (LB), pod biomass $(P B), 100$-seed weight (SW), seed yield (SY), stomatal conductance (SC), leaf water potential (WP) in KATB1/GLP2 F2 population under non-stress and drought stress conditions

\begin{tabular}{|c|c|c|c|c|c|c|c|c|c|}
\hline Trait & QTL & Trt & $\mathrm{Pv}$ & $\begin{array}{l}\text { QTL } \\
\text { position }\end{array}$ & Flanking marker & $\begin{array}{l}\text { LOD } \\
\text { score }\end{array}$ & $\begin{array}{l}\text { LOD } \\
\text { threshold }\end{array}$ & $\mathrm{R}^{2}$ & $\begin{array}{l}\text { Additive } \\
\text { effect }\end{array}$ \\
\hline $\begin{array}{l}\text { Number of } \\
\text { branches per } \\
\text { plant }\end{array}$ & $\mathrm{NB} 1.1^{\mathrm{KG}}$ & DS & 1 & 5.56 & sc00258ln515763_1856 & 3.1 & 2.28 & 11.25 & 0.34 \\
\hline \multirow{3}{*}{$\begin{array}{l}\text { Number of seeds } \\
\text { per pod }\end{array}$} & NG1.1 $1^{\mathrm{KG}}$ & DS & 1 & 23.52 & sc00564ln943697_6815 & 4.31 & 3.02 & 10.65 & -0.06 \\
\hline & $\mathrm{NG} 2.1^{\mathrm{KG}}$ & DS & 2 & 21.65 & sc00117ln943287_1165 & 3.88 & 2.63 & 10.23 & 0.68 \\
\hline & NG8.1 $1^{\mathrm{KG}}$ & DS & 8 & 0.11 & sc00564ln856573_3755 & 2.06 & 1.82 & 12.64 & -0.55 \\
\hline \multirow{4}{*}{$\begin{array}{l}\text { Number of pods } \\
\text { per plant }\end{array}$} & $\mathrm{NP} 1.1^{\mathrm{KG}}$ & DS & 1 & 15.38 & sc01264ln932625_2212 & 8.24 & 3.59 & 17.67 & 0.34 \\
\hline & $\mathrm{NP} 3.1^{\mathrm{KG}}$ & ww & 3 & 7.02 & sc00518ln692941_3545 & 5.31 & 2.51 & 17.01 & 0.19 \\
\hline & $\mathrm{NP} 2.1^{\mathrm{KG}}$ & DS & 2 & 25.64 & sc00339ln939425_4385 & 4.81 & 3.86 & 24.35 & 0.25 \\
\hline & $\mathrm{NP} 3.1^{\mathrm{KG}}$ & DS & 3 & 7.02 & sc00369ln874451_2254 & 4.24 & 2.66 & 6.84 & 0.08 \\
\hline \multirow{3}{*}{$\begin{array}{l}\text { Days to } \\
\text { flowering }\end{array}$} & DF1.1 $1^{\mathrm{KG}}$ & ww & 1 & 14.23 & sc00023ln763611_6414 & 3.37 & 2.67 & 12.62 & 0.15 \\
\hline & DF2.1 $1^{\mathrm{KG}}$ & DS & 2 & 10.56 & sc00564ln882990_3214 & 3.52 & 2.91 & 6.45 & 0.04 \\
\hline & DF4.1 $1^{\mathrm{KG}}$ & DS & 4 & 23.45 & sc00439ln772650_2216 & 5.03 & 2.11 & 10.25 & 0.31 \\
\hline \multirow[b]{2}{*}{ Days to maturity } & $\mathrm{DM} 1.1^{\mathrm{KG}}$ & ww & 1 & 44.3 & sc00517ln941037_2554 & 3.26 & 2.08 & 16.00 & 0.12 \\
\hline & DM4.1 ${ }^{\mathrm{KG}}$ & DS & 4 & 12.78 & sc00325ln677312_7402 & 3.65 & 2.46 & 12.36 & -0.07 \\
\hline \multirow[b]{2}{*}{ Stem biomass } & SB1.1 $1^{\mathrm{KG}}$ & DS & 1 & 45.55 & sc00734ln523622_8765 & 3.47 & 2.64 & 21.49 & 0.17 \\
\hline & SB2.1 ${ }^{\mathrm{KG}}$ & DS & 2 & 11.04 & sc006931n835947_5841 & 3.22 & 2.17 & 17.58 & 0.35 \\
\hline Leaf biomass & $\mathrm{LB} 2.1^{\mathrm{KG}}$ & DS & 2 & 9.03 & sc008901n923464_1254 & 2.64 & 2.12 & 18.52 & -0.01 \\
\hline Pod biomass & $\mathrm{PB} 1.1^{\mathrm{KG}}$ & DS & 1 & 23.45 & sc00563ln950218_6547 & 3.77 & 2.96 & 23.28 & 0.02 \\
\hline Seed weight & SW8.1 $1^{\mathrm{KG}}$ & ww & 8 & 32.45 & sc00064ln987325_7202 & 3.96 & 3.62 & 9.65 & 0.32 \\
\hline \multirow[b]{2}{*}{ Seed yield } & SY1.1 $1^{\mathrm{KG}}$ & ww & 1 & 11.78 & sc00045ln763729_3325 & 4.08 & 2.90 & 12.06 & -0.41 \\
\hline & SY2.1 ${ }^{\mathrm{KG}}$ & DS & 2 & 37.47 & sc01585ln034402_5351 & 3.76 & 2.65 & 10.70 & -0.05 \\
\hline \multirow{2}{*}{$\begin{array}{l}\text { Stomatal } \\
\text { conductance }\end{array}$} & SCO3.1 ${ }^{\mathrm{KG}}$ & ww & 3 & 22.14 & sc00004ln982325_3165 & 3.57 & 2.35 & 10.43 & -1.18 \\
\hline & SCO4.1 ${ }^{\mathrm{KG}}$ & DS & 4 & 0.80 & sc01235ln698241_2417 & 3.95 & 3.72 & 18.51 & -0.24 \\
\hline $\begin{array}{l}\text { Leaf water } \\
\text { potential }\end{array}$ & LWP1.1 ${ }^{\mathrm{KG}}$ & DS & 1 & 5.54 & sc00387ln936125_7264 & 4.35 & 3.4 & 12.01 & -0.03 \\
\hline
\end{tabular}

QTL; quantitative trait loci, LOD; logarithm of odds, Trt- treatment, PV-Polycythemia Vera, $R^{2}$ - adjusted coefficient of determination

Each QTL explained varied amount of phenotypic variance (between 6.45 and $23.28 \%$ ) among the traits while the values for the LOD scores varied between 2.6 and 7.7 (Table 4). Six QTLs with major effect (LOD $\geq 3.0$ ) located on 4 chromosomes; Pv01, Pv02, Pv04 and Pv08 were detected in the experiment, eighteen under drought stress while five were detected under well-watered treatment. The number of pods per plant had the highest number of QTLs (4) detected but spread on different chromosomes. Two QTLs; NG1.1 KG and NP1.1 KG associated with the number of pods per plant and number of grains per pod were detected under drought stress conditions on chromosomes Pv01 flanked by SNP markers sc00564ln943697_6815 and sc01264ln932625_2212 respectively. Two other QTLs; NG2.1 ${ }^{\mathrm{KG}}$ and NG8.1 $\mathrm{KG}$ associated with the number of grains were expressed under drought stress conditions but on different linkage groups. For example, NG2.1 $\mathrm{KG}$ was detected on Pv02 while NG8.1KG was detected on Pv08. QTLs for pods number were also detected on chromosomes Pv02 and Pv03. These two QTLs increased grain yield per pod in drought tolerant F2 by an average of 1.2 and $2.5 \mathrm{~g}$ (Table 1) and explained 2.06 and $3.88 \%$ of the phenotypic variation respectively. The positive effects of these QTLs were from the KATB1 parent (Table 4).

A constitutive QTL associated with days to maturity (DM1.1 $\mathrm{KG}$ ) detected on chromosome Pv01 under well-watered conditions co-localized with other QTL associated with the number of branches per plant (NB1.1 $\mathrm{KG})$, stem biomass $\left(\mathrm{SB} 1.1^{\mathrm{KG}}\right)$, pod biomass $\left(\mathrm{PB} 1.1^{\mathrm{KG}}\right)$, seed yield (SY1.1 ${ }^{\mathrm{KG}}$ ), and leaf water potential (LWP1.1 ${ }^{\mathrm{KG}}$ ) detected under drought stress. One seed yield 
QTL identified in Pv02 and one QTL for stomatal conductance identified in Pv04 under well-watered treatments were contributed by the GLP2 parent. Two QTLs for seed yield mapped to chromosomes Pv01 and Pv02 were identified under drought stress conditions. The seed yield QTLs were located close to SNP markers sc00045ln763729_3325

and sc01585ln034402_5351 respectively. The QTL for seed yield on chromosome $\mathrm{Pv} 02$ was associated with QTL for the number of grains per pod (NG2.1 ${ }^{\mathrm{KG}}$ ), and co-localized with QTLs for days to flowering (DF2.1 ${ }^{\mathrm{KG}}$ ) and leaf biomass (LB2.1 ${ }^{\mathrm{KG}}$ ). Under drought treatment QTLs for stem biomass, pod biomass and number of pods per plant showed the greatest phenotypic variations associated with drought tolerance (21.49\%, 23.28\% and 24.35\%). These QTLs were tagged near the SNP marker sc00734ln523622_8765 marker in Pv01, SNP marker sc00563ln950218_6547 also in Pv01 and the SNP marker sc00339ln939425_4385 in Pv02, respectively.

The two stomatal conductance QTLs mapped on chromosome $\mathrm{Pv} 03$ and Pv04 both explained $30.94 \%$ of the phenotypic variance with LOD score of 3.57 and 3.95 flanked by SNP markers sc00004ln982325_3165 and sc01235ln698241_2417 respectively. Though these QTLs appeared on different chromosomes, they were detected under same conditions of drought stress. The QTL for number of pods per plant mapped on Pv02 contributed by the KATB1 parent, showed the greatest amount of phenotypic variance of $24.35 \%$ associated with drought tolerance. Number of pods per plant and days to maturity each received a positive allele from KATB1 under well-watered treatment, whereas GLP2 contributed negative alleles for seed yield under both treatments (Table 4).

\section{Discussion}

Breeding for drought tolerance using conventional plant breeding methods not only take a long to come up with elite varieties but also requires huge investment of resources. Furthermore, problems associated with environmental sensitivity combined with complex physiological interactions often reduces the potential of associating traits to agronomic benefits. Thus, identification of markers that can facilitate the selection of genotypes with drought tolerant traits at an early stage of crop development program would ensure rapid release of a new variety. Besides offering an opportunity to select for traits of interest, markers linked to complex traits can also be useful in a negative selection programme to select against negative characteristics.

With the challenges at hand and opportunities presented, the current study was conducted to detect the various QTLs controlling traits associated with drought tolerance in common beans with the aim of providing valuable information that could potentially be used in markers-assisted selection in the common bean breeding improvement programs. An F2 population developed from across of drought tolerant (KATB1 cultivar) and drought susceptible (GLP2 cultivar) was evaluated to map QTL for drought tolerance traits. Generally, the success of QTL mapping relies heavily on the marker density [29, 34, 35]. In essence, a highly saturated map can enhance the precision of QTL mapping. In this study, a fairly dense genetic map was developed from 374 SNPs mapped on KATB1/GLP2 RIL genome spanning a total length of $754 \mathrm{cM}$ at an average distance of 2.02 $\mathrm{cM}$ between adjacent markers thus, compares favorably with previously constructed genetic maps of common bean. Given that widely grown common bean varieties in Kenya are Andean derivatives, the successful construction of a genetic map using an Andean intragenic cross population will immensely contribute to understanding the genetic control mechanism of drought tolerance among the local bean genotypes.

Although several QTLs related to drought tolerance have been identified in different studies $[3,36,37]$ it is still a challenge to find QTLs with stable expression under different stress environment due to the quantitative nature of drought which is highly influenced by prevailing environmental conditions. In the present study, a total of 23 QTLs related to drought tolerance in common bean genome with effects ranging 
between 6.45 and $24.35 \%$ were identified and mapped, majority of which were in regions where other QTLs for similar traits were previously reported. A greater number of the QTLs were detected under drought stress compared to wellwatered conditions. This indicates that most of the identified QTLs has adaptive nature to drought stress. Further, the maternal parent KATB1 contributed a higher number $(78 \%)$ of QTLs identified in this study. These findings, therefore, confirms the suitability of KATB1 as a source of drought tolerance.

QTLs were mapped to different locations throughout the genome with certain regions hosting more than one QTL associated with multiple traits. This could be as a result of correlation existing between these traits. QTLs for correlated traits were localized on the same chromosome and the primary reason for this could be that these traits are associated on cause effect basis indicating that these traits are controlled by genes that are tightly linked [38, 39]. In this study, co-localization of QTLs for days to flowering and days to maturity, stem biomass and pod biomass was evident on chromosome Pv01. Unsurprisingly, days to flowering and days to maturity were strongly correlated with accumulated biomass under drought stress treatment. QTLs for days to maturity and seed yield were noticed to coincide on chromosome Pv02. In this study, QTLs conditioning days to flowering and maturity were mapped to chromosome Pv01 and PV04 under well-watered and drought stress treatment respectively. Prior research by [29] had reported the co-localization of the same QTL on chromosome Pv04 for flowering and maturity in the SEA5/CAL96 RIL population. A photoperiod gene on chromosome Pv04 with major effect on partitioning of assimilates between vegetative and reproductive growth that was previously described by [40] is likely to be the same QTLs for days to flowering and maturity reported in this study.

An important QTL (NP3.1 ${ }^{\mathrm{KG}}$ ) (LOD score = 5.31) for number of pods per plant found under both drought stress and well-watered conditions responsible for between 6.84 and $17.01 \%$ of the phenotypic variation was mapped to chromosome Pv03. This QTL may be related to stomatal conductance QTL (SCO3.1 ${ }^{\mathrm{KG}}$ ) (LOD score $=3.57$ and $10.43 \%$ variance explanation) on Pv03 detected under well-watered conditions. This linkage could offer a chance to select simultaneously for number of pods per plant and stomatal conductance in an intragenic pool cross. Loci associated with leaf biomass and stem biomass (LB2.1 ${ }^{\mathrm{KG}}$ and SB2.1 ${ }^{\mathrm{KG}}$ ) were expressed in drought stress treatment and were linked to yield traits in chromosome Pv02. This overlapping is a strong indication of the important role stem and leaf biomass could play in controlling seed yield under drought stress. Although some studies have detected QTL associated with stem biomass and some yield components traits [21] co-localization with yield trait on the same region has not been reported in other studies. A 100-seed weight QTL (SW8.1 KG) with a LOD score of 3.96 and $9.65 \%$ variance appearing on chromosome $\mathrm{Pv} 08$ is another significant trait in this study consistent under both water treatment. Reference [35] reported QTLs controlling 100-seed weight located on chromosome Pv08 although those QTLs demonstrated higher genetic variance and were mapped towards the mid-point of chromosome $\mathrm{Pv} 08$. The variations could have been due to type of markers used, environment factors or genetic origin of the parents used to produce the F2 population.

In this study the number of pods per plant correlated strongly with seed yield in both treatments implying that some genes responsible for number of pods per plant are linked with genes controlling seed yield. The lack of overlap between the QTLs for stomatal conductance and leaf water potential indicates the independence of these physiological parameters from each other. Days to maturity was negatively correlated with seed yield under drought stress treatment, implying that maturity is an important strategy in drought evasion. Plasticity as an adaptation mechanism to drought stress in common bean has been reported in several studies [13, 10, 41, 42].

In this study, besides the occurrence of colocalization of QTLs for multiple traits, most of the detected QTLs were exclusively mapped to either well-watered or drought stress treatment 
demonstrating that QTLs showed different behavioural pattern for genetic control of traits such as stomatal conductance and leaf water potential under variable water conditions. In this study stomatal conductance was strongly associated with seed yield under drought stress. This relationship supports similar findings on barley [43, 44]. The indirect use of stomatal conductance as selection criterion against drought tolerance has been reported in wheat [ 45 , $46,47,48,49]$. In this study some individuals in the population were able to maintain stomatal conductance as high as $43.6 \mathrm{mmol} \mathrm{m}-\mathrm{s}^{-1}$ while others as low as $19.5 \mathrm{mmol} \mathrm{m}-\mathrm{m}^{2} \mathrm{~s}^{-1}$. The individuals that were able to maintain higher levels of stomatal conductance throughout their reproductive phase under drought stress conditions produced better yields. From the result, this trait has the potential to be used in screening and selection of drought tolerant common bean genotypes.

\section{Conclusion}

The molecular linkage map constructed from 120 F2 lines from a cross between KATB1-drought tolerant genotype and GLP2 - drought susceptible genotype was sufficient to detect QTL for number of branches per plant, pods number per pant, grain/seed number per pod, seed weight, -seed yield, days to flower, days to maturity, stem biomass, pod biomass, leaf biomass, stomatal conductance, and leaf water potential in this study. A previous study mapped regions containing drought related QTLs that are in agreement with some of the findings from this study. For instance, QTL associated with days to flowering and days to maturity were detected on Pv04, and Pv01 and 100-seed weight on Pv08, similar to others previously reported. Regions containing QTL associated with drought related traits that have never been reported in elsewhere in other studies were identified in the current study. For example, QTL (SCO4.1KG) controlling stomatal conductance on Pv04, and QTL (LWP1.1KG) associated with leaf water potential and putatively involved in drought adaptation mechanisms. Analyses of the common bean to obtain the precise location of the candidate gene flanking these new complex traits would be an important step in sorting out individual components which can be used for selection. Nevertheless, no single QTL was detected on Pv05, Pv06, Pv07, Pv09, Pv10 and Pv11 in this study. Overall, more QTLs were detected under drought stress than well-watered treatment. Our study succeeded in identifying the specific genetic regions (QTL) that will be helpful in marker-assisted exploitation of the existing genetic variability within the common bean germplasm to improve drought tolerance. In addition, the identified genetic factors will increase the efficiency of screening and selection therefore, providing good prospects for crop breeding programs in Kenya and the region. A larger population (more than $200 \mathrm{~F} 2 \mathrm{~s}$ ) developed either from parents of the same genotypes (as was the case in this study) or from closely related genotypes is needed to construct a dense linkage map to verify and confirm the possible linkage or pleiotropy of detected QTLs in this study. This study recommends simultaneous use of genomic and phenotypic tools in order to reduce time required for screening and selection of genotypes for tolerance to drought stress.

\section{Competing Interests}

Author(s) declared that no conflict of interest exist in the publication of this work.

\section{How to Cite this Article:}

C. Langat, O. Ombori, R. Cheruiyot, M. Gathaara, D. Karanja, and P. Leley, "Mapping of Quantitative Trait Loci (QTL) Related to Drought Tolerance in Common Bean (Phaseolus vulgaris L.) Using F2 Population from (KATB1 X GLP2)", Int. Ann. Sci., vol. 8, no. 1, pp. 7586, Oct. 2019. doi: 10.21467/ias.8.1.75-86

\section{References}

[1] Rao, I. M. (2014). Advances in improving adaptation of common bean and Brachiaria forage grasses to abiotic stresses in the tropics, in Handbook of Plant and Crop Physiology, ed. M. Pessarakli (Boca Raton, FL: CRC Press; Taylor and Francis Group), 847-889.

[2] Rippke, U., Ramirez-Villegas, J., Jarvis, A., Vermeulen, S. J., Parker, L., and Mer, F., (2016). Timescales of transformational climate change adaptation in subSaharan African agriculture. Nature Climate Change, 6: 605-609.

[4] Beebe, S. E., Rao, I. M., Blair, M. W., and AcostaGallegos, J. A. (2013). Phenotyping common beans for adaptation to drought. Frontiers in Physiology, 4: 35.

[5] Ambachew, D., Mekbib, F., Asfaw, A., Beebe, S.E., and Blair, M.W. (2015). Trait relations in common bean 
genotypes grown under managed-stress for drought and field infestation of bean fly. The Crop Journal, 3: 305316.

[7] Dai, A. (2013). Increasing drought under global warming in observations and models. Nature Climate Change, 3: 52.

[8] FAOSTAT (2015). Agricultural production, crop primary database. Available: http:// faostat3.fao.org/browse/Q/QC/E [2016, September 23].

[9] Rao, I. M., (2001). Role of physiology in improving crop adaptation to abiotic stresses in the tropics: The case of common bean and tropical forages, pp. 583-613 in Handbook of Plant and Crop Physiology, edited by M. Pessarakli. Marcel Dekker, Inc., New York.

[10] Polania, J., Rao, I. M., Cajiao, C., Rivera, M., Raatz, B., and Beebe, S. (2016). Physiological traits associated with drought resistance in Andean and Mesoamerican genotypes of common bean (Phaseolus vulgaris L.). Euphytica, 210: 17-29.

[11] Singh, S.P. (1992). Common bean improvement in the tropics. Plant Breeding Reviews, 10: 199-269.

[12] Assefa, T., Rao, I.M., Cannon, S.B., Wu, J., Gutema, Z., Blair, M.W., Paul, O., Alemayehu, A., and Dagne, B. (2017). Improving adaptation to drought stress in white pea bean (Phaseolus vulgaris L.) genotypic effects on grain yield, yield components and pod harvest index. Plant Breeding, 136: 548-561.

[13] Acosta-Gallegos, J., and White, J. W. (1995). Phenological plasticity as an adaptation by common bean to rain-fed environments; Crop Science, 35(1): 199-204.

[13] Asfaw, A.A., Almekinders, C.J.M., Struick, P.C., and Blair, M.W. (2013). Farmers' common bean variety and seed management in the face of drought and climate instability in southern Ethiopia. Science Research Essays, 8: 1022-1037.

[14] Miklas, P.N., Delorme, R., and Riley, R. (2003). Identification of QTL conditioning resistance to white mold in snap bean. Journal of the American Society for Horticultural Science, 128: 564-570.

[15] Araújo, S. S., Beebe, S., Crespi, M., Delbreil, B., Gonzalez, E. M., and Gruber, V. (2015). Abiotic stress responses in legumes: strategies used to cope with environmental challenges. CRC. Critical Reviews in Plant Science, 34: 237-280.

[16] Porch, T.G., Ramirez, V.H., Santana, D., and Harmsen, E.W. (2009). Evaluation of common bean for drought tolerance in Juana Diaz, Puerto Rico. Journal of Agronomy and Crop Science, 195: 328-334.

[17] Assefa, T., Wu, J., Beebe, S., Rao, I. M., Marcomin, D., and Claude, R. J. (2015). Improving adaptation to drought stress in small red common bean: phenotypic differences and predicted genotypic effects on grain yield, yield components and harvest index. Euphytica, 303: 477-489.

[18] Schneider, K.A., Brothers, M.E., and Kelly, J.F. (1997). Marker-assisted selection to improve drought resistance in common bean. Crop Science, 37: 51-60.

[19] Collins, N. C., Tardieu, F., and Tuberosa, R. (2008). Quantitative trait loci and crop performance under abiotic stress: where do we stand; Plant physiology, 147(2): 469-486.

[20] Blair, M. W., Galeano, C. H., Tovar, E., Torres, M. C. M., Castrillón, A. V., Beebe, S. E., and Rao, I. M. (2012). Development of a Mesoamerican intra-genepool genetic map for quantitative trait loci detection in a drought tolerant $\times$ susceptible common bean (Phaseolus vulgaris L.) cross; Molecular Breeding, 29(1): 71-88.

[21] Asfaw, A., and Blair, M. W. (2012). Quantitative trait loci for rooting pattern traits of common beans grown under drought stress versus non-stress conditions. Molecular Breeding, 30: 681-695.

[22] Katungi, E., Farrow, A., Mutuoki, T., Gebeyehu, S., Karanja, D., Alamayehu, F., Sperling, L., Beebe, S., Rubyogo, J.C., and Buruchara, R. (2010). Improving common bean productivity: An analysis of socioeconomic factors in Ethiopia and Eastern Kenya. Baseline Report Tropical Legumes II, CIAT. Cali, Colombia.

[23] Mahuku, G. S. (2004). A simple extraction method suitable for PCR based analysis of plant, fungal, and bacterial DNA. Plant Molecular Biology Reporter, 22: 71-81.

[24] Van Ooijen, J.W. (2006). JoinMap4. Software for the calculation of genetic linkage maps in experimental populations. Kyazma, B.V., Wageningen, the Netherlands.

[25] Kosambi, D. D. (1994). The estimation of map distance from recombination values. Annals of Eugenics, 12: 12172-12175.

[26] Goodstein, D.M., Shu, S., Howson, R., Neupane, R., Hayes, R.D., Fazo, J., Mitros, T., Dirks, W., Hellsten, U., Putnan, N., and Rokhsar, D.S. (2012). Phytozome: a comparative platform for green plant genomics. Nucleic Acid Research, 40: 1178-1186.

[27] Schmutz, J., McClean, P. E., Mamidi, S., Albert Wu, G., Cannon, S. B., Grimwood, J., and Jenkins, J. (2014). A reference genome for common bean and genome-wide analysis of dual domestications. Nature Genetics, 46: 707-713.

[28] Wang, J., Li, H., Zhang, L., and Meng L. (2014). Users' manual of QTL IciMapping. The quantitative genetics group, institute of crop science, Chinese Academy of Agricultural Sciences (CAAS), Beijing 100081, China, and Genetic Resources Program, International Maize and Wheat Improvement Center (CIMMYT), Apdo. Postal 6 $\pm 641,06600$ Mexico.

[29] Mukeshimana, G., Butare, L., Cregan, P.B., Blair, M.W., and Kelly, J.D. (2014). Quantitative trait loci associated with drought tolerance in common bean. Crop Science, 54: 923-938.

[30] Churchill, G.A., and Doerge, R.W. (1994). Empirical threshold values for quantitative trait mapping. Genetics, 138: 963-971.

[31] Miklas, P.N., Kelly, J.D., Beebe, S.E., and Blair, W.M. (2006). Common bean breeding for resistance against biotic and abiotic stresses: from classical to MAS breeding. Euphytica, 147: 106-131.

[32] Ender, M., Terpstra, K., and Kelly, J.D. (2008). Markerassisted selection for white mold resistance in common bean. Molecular Breeding, 21: 149-157.

[33] SAS Institute. (2011). SAS version 9.3. SAS Institute Inc., Cary, NC.

[34] Beebe, S., Rao, I. M., Devi, M., and Polania, J. (2014). Common beans, biodiversity, and multiple stress: challenges of drought resistance in tropical soils. Crop Pasture Science, 65: 667-675.

[35] Trapp, J.J., Urrea, C., Cregan, P.B., and Miklas, P.N. (2015). Quantitative Trait Loci for Yield under Multiple Stress and Drought Conditions in a Dry Bean Population. Crop Science, 55: 1596. 
[36] Blair, M.W., Iriarte, G., and Beebe, S.E. (2006). QTL analysis of yield traits in an advanced backcross population derived from a cultivated Andean $\mathrm{x}$ wild common bean (Phaseolus vulgaris L.) cross. Theoretical and Applied Genetics, 112: 1149-1163.

[37] Asfaw, A., Ambachew, D., Shah, T., and Blair, M.W. (2017). Trait Associations in Diversity Panels of the Two Common Bean (Phaseolus vulgaris L.) Gene Pools Grown under Well-watered and Water-Stress Conditions. Frontiers in Plant Science, 8: 733.

[38] Tuberosa, R., Salvi, S., Sanguineti, M.C., Landi, P., Maccaferri, M., and Conti, S. (2002). Mapping QTLs regulating morpho-physiological traits and yield: case studies, shortcomings and perspectives in droughtstressed maize. Annals of Botany, 89: 941-963.

[39] Terán, H., and Singh, S. P. (2002). Selection for drought resistance in early generations of common bean populations; Canadian journal of plant science, 82(3): 491-497.

[40] Tar'an, B., Michaels, T. E., and Pauls, K. P. (2002). Genetic mapping of agronomic traits in common bean; Crop Science, 42(2): 544-556.

[41] Rosales-Serna, R., Kohashi-Shibata, J., AcostaGallegos, J. A., Trejo-López, C., Ortiz-Cereceres, J., and Kelly, J. D. (2004). Biomass distribution, maturity acceleration and yield in drought-stressed common bean cultivars. Field Crop Research. 85: 203-211.

[42] Urrea, C.A., Yonts, C.D., Lyon, D.J., and Koehler, A.E. (2009). Selection for drought tolerance in dry bean derived from the Mesoamerican gene pool in Western Nebraska. Crop Science, pp. 49.

[43] Chloupek, O., Dostál, V., Středa, T., Psota, V., and Dvořáčková, O. (2010). Drought tolerance of barley varieties in relation to their root system size. Plant Breeding, 129: 630-636.

[44] González, A., and Ayerbe, L. (2010). Effect of terminal water stress on leaf epicuticular wax load, residual transpiration and grain yield in barley. Euphytica, 172: 341-349.

[45] Fischer, R., Rees, D., Sayre, K. D., Lu, Z.M., Condon, A.G., and Saavedra, A.L. (1998). Wheat yield progress associated with higher stomatal conductance and photosynthetic rate, and cooler canopies. Crop Science, 38: 1467-1475.

[46] Blum, A. (2009). Effective use of water (EUW) and not water-use efficiency (WUE) is the target of crop yield improvement under drought stress. Field Crops Research, 112: 119-123.

[47] Bennett, D., Reynolds, M., Mullan, D., Izanloo, A., Kuchel, H., Langridge, P., and Schnurbusch T. (2012). Detection of two major grain yield QTLs in bread wheat (Triticum aestivum $\mathrm{L}$.) under heat, drought and high yield potential environments. Theoretical and Applied Genetics, 125: 1473-1485.

[48] Roche, D. (2015). Stomatal conductance is essential for higher yield potential of $\mathrm{C} 3$ crops. Critical Reviews in Plant Sciences, 34: 429-453.

[49] Ouyang, W., Struik, P. C., Yin, X., and Yang, J. (2017). Stomatal conductance, mesophyll conductance, and transpiration efficiency in relation to leaf anatomy in rice and wheat genotypes under drought. Journal of Experimental Botany, 68: 5191-5205.
Publish your research article in AIJR journals-

$\checkmark \quad$ Online Submission and Tracking

$\checkmark \quad$ Peer-Reviewed

$\checkmark \quad$ Rapid decision

$\checkmark \quad$ Immediate Publication after acceptance

$\checkmark \quad$ Articles freely available online

$\checkmark \quad$ Retain full copyright of your article.

Submit your article at journals.aijr.in

\section{Publish your books with AIJR publisher- \\ $\checkmark \quad$ Publish with ISBN and DOI. \\ $\checkmark$ Publish Thesis/Dissertation as Monograph. \\ $\checkmark \quad$ Publish Book Monograph. \\ $\checkmark \quad$ Publish Edited Volume/ Book. \\ $\checkmark \quad$ Publish Conference Proceedings \\ $\checkmark \quad$ Retain full copyright of your books. \\ Submit your manuscript at books.aijr.org}

